\title{
Phillips Curve in Brazil: An Unobserved Components Approach
}

\author{
Vicente da Gama Machado \\ Pesquisador - Banco Central do Brasil \\ Endereço: SBS - Quadra 3 - Bloco B - Edifício-Sede, Brasília/DF - Brasil \\ CEP: 70074-900 - E-mail: vicente.machado@bcb.gov.br \\ Marcelo Savino Portugal \\ Professor - Universidade Federal do Rio Grande do Sul (UFRGS) \\ Av. João Pessoa, 52 - sala 33 B - Porto Alegre/RS - Brasil \\ CEP: 90040-000 - E-mail: msp@ufrgs.br \\ Recebido em 14 de agosto de 2012. Aceito em 19 de março de 2014.
}

\begin{abstract}
This paper estimates reduced-form Phillips curves for Brazil with a framework of time series with unobserved components, in the spirit of Harvey (2011). However, we allow for expectations to play a key role using data from the Central Bank of Brazil's Focus survey. Besides GDP, we also use industrial capacity utilization rate and IBC-Br index, as measures of economic activity. Our findings support the view that Brazilian inflation targeting has been successful in reducing the variance of both the seasonality and level of the inflation rate, at least until the beginning of the subprime crisis. Furthermore, inflation in Brazil seems to have responded gradually less to measures of economic activity in recent years. This provides some evidence of a flattening of the Phillips curve in Brazil, a trend previously shown by recent studies for other countries.
\end{abstract}

\section{Keywords}

New Keynesian Phillips curve, inflation, unobserved components

\section{Resumo}

Este artigo estima curvas de Phillips para o Brasil com uma abordagem de séries temporais com componentes não observados, seguindo Harvey (2011). Entretanto, é conferido um papel central a expectativas utilizando dados do Boletim Focus do Banco Central do Brasil. Além do PIB, empregamos a taxa de utilização da capacidade industrial e uma série ainda pouco explorada, IBC-Br, como medidas de atividade econômica. Os resultados apoiam a visão que o sistema de metas no Brasil tem sido bem-sucedido em reduzir a variância na sazonalidade e no nível da taxa de inflação, ao menos até o início da crise imobiliária americana. Além disso, a inflação parece ter respondido gradualmente menos a medidas de atividade no período recente. Tal fato constitui uma evidência de achatamento da Curva de Phillips no Brasil, tendência observada em estudos recentes de outros países.

- We thank seminar participants at the Central Bank of Uruguay for helpful comments. The views expressed here are those of the authors and do not necessarily reflect those of the Central Bank of Brazil. 


\section{Palavras-Chave}

Curva de Phillips Novo-Keynesiana, inflação, componentes não observados

Classificação JEL

C32, E31

\section{Introduction}

The Phillips curve has unsurprisingly been a recurrent subject of debate in macroeconomics, since its formulation encompasses an important trade-off between inflation rate and unemployment rate or alternatively between inflation rate and output gap. Numerous countries use this aggregate supply relation when formulating and implementing monetary policy, often jointly with an aggregate demand equation (IS) and an interest rate rule. The Phillips curve is also frequently employed in inflation forecasting models, as reviewed by Stock and Watson (2008).

Over the past few years, the new Keynesian Phillips curve (NKPC) has become a popular framework. Its initial formulation, mainly attributed to Calvo (1983), consisted of a connection between inflation and real marginal cost plus an inflation expectations component, where the driving force was the observed behaviour of sticky price adjustment by some firms. A large literature has addressed important critiques to some aspects of the NKPC, such as price adjustments features and the persistence of observed inflation, not contemplated in the original equation. On the macroeconomic side, the coefficient of real marginal cost may even be negative, which is economically counterintuitive, as Rudd and Whelan (2007) mentioned. Even the widely adopted hybrid new Keynesian Phillips curve, which includes lagged inflation, has not been successful in adequately explaining inflation dynamics. According to Rudd and Whelan (2007), this occurs both when output gap and labour income share are used as proxies for real marginal cost. Mavroeidis (2005) also assesses identification issues in the estimation of forward-looking rational expectations models using GMM. The success of Phillips curve estimations for the recent past of the Brazilian economy is equally questionable, as pointed out by Sachsida, Ribeiro and Santos (2009). 
The focus of this study is to estimate alternative Phillips curves with unobserved components for the Brazilian economy, following to some extent the parsimonious approach proposed by Harvey (2011). A simple relationship is established between monthly inflation and output data, in which inflation is explained by a set of unobserved components (UC), in addition to the usual output gap and expected inflation terms. As a first step, output gap is identified by extracting the cycle from the appropriate output series, also by the UC method. ${ }^{1}$

Differently from Harvey (2011), the inflation expectations term is explicitly introduced in the Phillips curve. Since we do not aim to impose rational expectations from the outset, we use data from the Central Bank of Brazil's FOCUS survey, based on subjective expectations from a sample of firms. The stochastic trend component can be regarded as core inflation, substituting the lagged term of the hybrid NKPC. By adding the usual term corresponding to marginal cost, our model resembles a standard hybrid NKPC. Thereafter, a multivariate estimation is conducted, in which the appropriate output gap is implicitly present in the output equation, instead of being inserted exogenously, which has the advantage of avoiding the previous estimation of an additional unobserved component. Harvey's "similar cycles" approach follows naturally since the cyclical movements of the two series are assumed to arise as a result of a common business cycle.

A secondary contribution concerns the use of output gap obtained from a trend-cycle decomposition of the Brazilian Central Bank's index of economic activity (IBC-Br). Notwithstanding the relatively small sample size, interesting conclusions can be drawn from this series. ${ }^{2}$ We extend the model allowing for time variation of the output gap parameter, which is also new in comparison to Harvey

1 Some authors (Gali and Gertler, 1999 and Schwartzman, 2006 and Sachsida, Ribeiro and Santos, 2009 in the Brazilian case) suggest that the output gap has not been a significant measure of inflationary pressures in GMM estimations. On the other hand, measures such as labour income share, or unit labor cost are also criticized for producing a countercyclical pattern in the analysis of U.S. data (Rudd and Whelan, 2007). As we introduce a different method for Brazilian series, we prefer to test the output gap, which is also an important policy variable for most central banks. However, capacity utilization rate and newly developed IBC-Br series are also considered.

2 This index was adopted by the Central Bank of Brazil in 2009, in order to follow up economic activity in a more tempestive fashion, due to its low occurrence of lags and to its monthly periodicity. According to the Brazilian Central Bank's Inflation Report of March 2010, the IBC-Br has evolved in considerably close connection to the GDP series. 
(2011). Some studies, as Kuttner and Robinson (2010), advocate a recent flattening of the Phillips curve in the US, in the sense that the output gap coefficient has become gradually smaller. This behaviour has important macroeconomic implications, as we discuss later. Finally, an analysis of the forecasting power is carried out by comparing our models with a simple forecasting model in order to test the assumption that Phillips curves may provide good inflation forecasts (Stock; Watson, 2008).

This paper is organized into six sections. The next section briefly reviews existing literature. Section 3 deals with the econometric estimation of Phillips curves with exogenous marginal cost measures, and the underlying conceptual issues. In section 4 we detail the multivariate estimation and its results, section 5 describes some extensions to the basic model, and Section 6 concludes.

\section{Related Literature}

Much of the literature that focuses on estimating the new Keynesian Phillips curve considers the inflation trend to be stationary, as reviewed by Rudd and Whelan (2007) and Nason and Smith (2008b). On the other hand, recent works have sought to model Phillips curves with a stochastic inflation trend, as done in the present study. Lee and Nelson (2007) propose a bivariate specification between inflation and unemployment, in which the inflation trend varies over time. Goodfriend and King (2009) explain the stochastic behaviour of inflation trend based on assumptions about central bank policy.

Concerning Phillips curves with unobserved components, Vogel (2008) uses a modeling strategy that resembles the one utilized in the present study, but instead her focus of inflationary pressures is the unemployment gap. Interestingly, her work combines the idea of Gordon's (1997) "triangle" model of inflation, in which the NAIRU (Non-Accelerating Inflation Rate of Unemployment) varies over time, with the new Keynesian model that focuses on short-term inflation dynamics. Harvey (2011) proposes decomposing recent US inflation into transitory and permanent components, following the methodology of structural time series models, described with more 
detail in Harvey (1989). However he does not consider inflation expectations, arguing that identification becomes difficult.

Our decision to use survey expectations directly in the estimations mirrors the seminal ideas from Roberts (1995), and more recently Adam and Padula (2011). ${ }^{3}$ The latter obtain significant estimates for the structural parameters once data from the Survey of Professional Forecasters are taken as proxy for expected inflation in the US.

With respect to the Brazilian literature on this issue, Sachsida, Ribeiro and Santos (2009) provide a good survey and propose a regime-switching model to account for time-variation in the Phillips curve parameters. Schwartzman (2006) estimates a Phillips curve using industrial capacity utilization data to address the fact that the output gap is not observable. Fasolo and Portugal (2004) adapt a NKPC for Brazil based on the NAIRU, emphasizing expectations formation. Arruda, Ferreira and Castelar (2008) and Correa and Minella (2005), used Phillips curve versions to assess their inflation forecasting power. To our knowledge, there are no Brazilian studies that investigate inflation dynamics with a primary focus on the decomposition of its factors into permanent and transitory unobserved components.

\section{Basic Model with Unobserved Components}

The main reference here is Harvey (2011), who used a structural time series approach with output gap as explanatory variable in a decomposition of the US inflation rate.

The specification with unobserved components has some advantages over ARMA models. First, the components here provide a straightforward economic interpretation.

3 Among studies that used inflation expectations surveys, Basistha and Nelson (2007), for instance, adopt an inverse perspective, in which they estimate the output gap using a forward-looking Phillips curve; Orphanides and Williams (2005) use data from the Survey of Professional Forecasters to estimate a model of the US economy, supposing private agents constantly learn as they form their forecasts. Henzel and Wollmershäuser (2008) argue that the use of survey expectations provide more reliable results for the Phillips curve in the Euro area than the GMM approach. 
But more importantly, in ARMA models, the dynamics relies exclusively upon the dependent variable, whereas in UC models, it is constantly inferred by observations. ${ }^{4}$

\subsection{Comments on Harvey (2011) and our Divergences}

Before moving on to the specification used, we make brief comments about Harvey's (2011) model and about the adaptations performed.

A basic structural ${ }^{5}$ time series model of inflation can be easily represented by:

$$
\begin{gathered}
\pi_{t}=\mu_{t}+\psi_{t}+\gamma_{t}+\varepsilon_{1 t} \\
\varepsilon_{1 t} \sim N\left(0,{\sigma_{\varepsilon_{1}}}^{2}\right)
\end{gathered}
$$

where the observed series $\pi_{t}$ is decomposed into trend $\left(\mu_{t}\right)$, cycle $\left(\psi_{t}\right)$, and seasonal $\left(\gamma_{t}\right)$ components, and into an irregular white noise component $\left(\varepsilon_{1 t}\right)$. In addition to permanent and transitory components, it is possible to add explanatory variables, and also structural breaks, level breaks and outliers, as in a usual regression. The trend component in (1), augmented with cycles and seasonals, represents the underlying level of inflation.

Adding an output gap term $h_{t}$ to Equation (1), as a measure of inflationary pressure, the result is a Phillips curve similar equation, using unobserved components:

$$
\begin{aligned}
\pi_{t}= & \mu_{t}+\psi_{t}+\gamma_{t}+\phi h_{t}+\varepsilon_{2 t} \\
& \varepsilon_{2 t} \sim N\left(0, \sigma_{\varepsilon_{2}}{ }^{2}\right)
\end{aligned}
$$

Harvey (2011) argues that, under some hypotheses, an inflation model with this configuration may simultaneously capture the backward- and forward-looking ideas of the hybrid new Keynesian

4 This point was made by Wongwachara and Minphimai (2009).

${ }^{5}$ Models with unobserved components are also known in the literature as structural time series models. See Harvey (1989). 
Phillips curve, ${ }^{6}$ which is notably based on lagged inflation, output gap and an inflation expectations component, like:

$$
\begin{aligned}
\pi_{t}= & \delta_{b} \pi_{t-1}+\phi h_{t}+\delta_{f} E_{t}\left(\pi_{t+1}\right)+\varepsilon_{3 t} \\
& \varepsilon_{3 t} \sim N\left(0, \sigma_{\varepsilon_{3}}{ }^{2}\right)
\end{aligned}
$$

In other words, Harvey (2011) focuses on estimating (2), assuming that this formulation contemplates the notion of a hybrid NKPC as in (3).

At least with respect to the lagged term, it is reasonable to affirm that it can be successfully replaced with the specification proposed here. It suffices to observe that a simple model that combines inflation and output gap $h_{t}$ :

$$
\begin{aligned}
\pi_{t}= & \mu_{t}+\phi h_{t}+\varepsilon_{4 t} \\
& \varepsilon_{4 t} \sim N\left(0, \sigma_{\varepsilon_{4}}{ }^{2}\right)
\end{aligned}
$$

can be written as:

$$
\begin{gathered}
\pi_{t}=E_{t-1}\left(\mu_{t}\right)+\phi h_{t}+v_{t} \\
v_{t} \sim N\left(0, \sigma_{v}{ }^{2}\right)
\end{gathered}
$$

where $v_{t}=\pi_{t}-E_{t-1}\left(\pi_{t}\right)$ is an innovation and $E_{t-1}\left(\mu_{t}\right)$ is a weighted average of past observations, corrected for the output gap's effect. If we include cycle and/or seasonal components in (5), we have the term $E_{t-1}\left(\mu_{t}\right)$ capturing both the past trend, and information on lagged inflation rates, appropriately weighted. This formulation seems to be more realistic than the Phillips curve with a plain lagged inflation term. In addition, as pointed out by Harvey (2011), admitting that $h_{t}$ is stationary in (4), the long-term inflation forecast is the current value of $\mu_{t}$, i.e., the unobserved term of the structural model becomes a measure of core inflation or underlying rate of inflation.

6 Gali and Gertler (1999) and Christiano, Eichenbaum and Evans (2005) are theoretical references on the treatment of inflation through the hybrid new Keynesian Phillips curve.

7 Nason and Smith (2008b) argue that the hybrid NKPC is consistent with a variety of price and information adjustment schemes. Therefore, the focus on reduced-form coefficients, $\delta_{b}$, $\phi$ and $\delta_{f}$, instead of on structural parameters, simplifies the analysis without interfering in the importance of the result. 
In regard to the expectations term, our view diverge from that adopted by Harvey (2011), which assumed that the hybrid NKPC is equivalent to an equation relating inflation to core inflation expectation, to expectation on the sum of future output gaps and to the current output gap, i.e.,

$$
\begin{gathered}
\pi_{t}=E_{t-1}\left(\mu_{t}^{*}\right)+\gamma \phi^{*} \sum_{j=o}^{\infty} \gamma^{j} E_{t}\left(h_{t+1+j}\right)+\phi h_{t}+v_{t} \\
v_{t} \sim N\left(0, \sigma_{v}{ }^{2}\right)
\end{gathered}
$$

In addition to the need to appeal to several simplifying assumptions, this does not fully solve the problem, i.e., it does not allow, in general terms, modeling the past and future effects of hybrid NKPC as in the equation with unobserved components, or in the present model, Equation (4). The author acknowledges the difficulty in doing so and places little importance on the future term, citing Rudd and Whelan (2007) and Nason and Smith (2008a).

Unlike Harvey (2011), ${ }^{8}$ we included an inflation expectations term in the analysis, as we consider it to be a crucial element when modeling inflation dynamics, in line with most of the new Keynesian literature. Furthermore, it is possible to check whether the future term indeed plays a major role for Brazilian data in our model, as highlighted by Sachsida, Ribeiro and Santos (2009). ${ }^{9}$ However, Nason and Smith (2008b) draw attention to the weak identification of traditional GMM-based estimates of the NKPC. More importantly, Orphanides and Williams (2005) point out that instrumental variables methods impose the unrealistic restrictions that monetary policy conduct and the formation of expectations are constant over time. These points further motivate the use of survey data in our study. ${ }^{10}$

\footnotetext{
8 Vogel (2008) also argues that inflation expectations should not be neglected in the basic equation, while citing the difficulty in the identification of $\mu_{t}$ in Harvey (2011) regarding past or future effects.

9 According to their model, studies that consider the Phillips curve to be nonlinear underestimate the role of the future term in the Brazilian inflation dynamics.

${ }^{10}$ On the other hand, some authors highlight the drawback of survey-based forecasting bias, as a sign of agents' lack of rationality. However, Araujo and Gaglianone (2010) state that survey series contained in the Central Bank of Brazil's Focus Bulletin do not suffer forecasting bias in the case of expectations over a shorter time horizon (one and three months ahead).
} 


\subsection{A Phillips Curve with Unobserved Components}

The link between resource utilization and inflation is at the heart of the Phillips curve. Therefore, we begin by considering some real activity variable that represents the inflationary pressure (or the real marginal cost, as in the original NKPC). The most frequent examples include labour income share, deviation from the natural rate of unemployment and the output gap. In the present study, the major focus is on the output gap, measured by two indicators of economic activity, GDP and the IBC-Br series, which is published by the Central Bank of Brazil (BCB). It is expected that with the gradual and larger availability of data after the introduction of the inflation targeting system, the output gap may become more representative of inflationary pressures in Brazil. ${ }^{11}$ Additionally, we reproduce the same estimations with an indicator of monthly industrial capacity utilization rate (ICU) series.

A large strand of the literature is devoted to the estimation of the output gap series, which is not directly observed in the economy. ${ }^{12}$ Since the primary goal here is not to explore these techniques, we opted for decomposing the logarithm of output into unobserved trend and cycle components, as in Harvey (2011).

$$
\begin{aligned}
& \log y_{t}=\mu_{t}+\gamma_{t}+\psi_{t}+\varepsilon_{t} \\
& \mu_{t}=\mu_{t-1}+\beta_{t-1} \\
& \beta_{t}=\beta_{t-1}+\zeta_{t}
\end{aligned}
$$

Simultaneously, we extracted the series seasonal component $\gamma_{t}$ and stochastic cycle $\psi_{t}$, which is equivalent to the output gap $h_{t}$ and takes on the following form:

$$
\left[\begin{array}{c}
\psi_{t} \\
\psi_{t}^{*}
\end{array}\right]=\rho_{\psi}\left[\begin{array}{cc}
\cos \lambda_{c} & \sin \lambda_{c} \\
-\sin \lambda_{c} & \cos \lambda_{c}
\end{array}\right]\left[\begin{array}{c}
\psi_{t-1} \\
\psi_{t-1}^{*}
\end{array}\right]+\left[\begin{array}{c}
\kappa_{t} \\
\kappa_{t}^{*}
\end{array}\right]
$$

\footnotetext{
${ }^{11}$ This is true both for the IBC-Br series and for usual GDP series.

12 The main tools used in the applied literature are: production function approach, which has the advantage of imposing some economic structure, with information on capital accumulation and on total factor productivity; and the econometric approach, in which the trend of the real GDP series is identified as potential output, a good and useful approximation when reliable macroeconomic data on capital and labour are not available.
} 
where $\rho_{\psi}$ is a damping factor and $\lambda_{c}$ in the frequency in radians $\left(0 \leq \lambda_{c} \leq \pi\right)$. Error terms $\varepsilon_{t}$ and $\zeta_{t}$ are normally independently distributed with variances $\sigma_{\varepsilon}^{2}$ and $\sigma_{\zeta}^{2} . \kappa_{t}$ and $\kappa_{t}^{*}$ are mutually uncorrelated disturbances with zero mean and common variances $\sigma_{\kappa}^{2}=\sigma_{\kappa^{*}}^{2}$. The dynamics of the stochastic seasonal component $\gamma_{t}$ is identical with the one described next in Equations (14) and (15). Note that the expression above indicates a smooth trend which, together with a cyclical component, represents an attractive decomposition for output data, according to Koopman et al. (2007). The trend described in (8) and (9) can also be referred to as an integrated random walk. A traditional tool for trend extraction is the Hodrick-Prescott (HP) filter. However, even if the resulting output gap is similar to the one obtained here, the HP filter tends to be less efficient at the end of the series, as described by Mise, Kim and Newbold (2005).

Our estimations begin with a simpler Phillips curve (model I), adapted from Harvey (2011), with the inclusion of interventions $\theta_{k, t}$ in order to capture irregularities in the data:

$$
\begin{gathered}
\pi_{t}=\mu_{t}+\gamma_{t}+\phi h_{t}+\sum_{k=1}^{l} d_{k} \theta_{k, t}+\varepsilon_{t} \\
\varepsilon_{t} \sim N\left(0, \sigma_{\varepsilon}{ }^{2}\right)
\end{gathered}
$$

where $\mu_{t}$ and $\gamma_{t}$ follow the same dynamics of Equations (13) through (15).

Adding the expectations term, we obtain the proposed Phillips curve model, which is classified as model II, III and IV in subsection 3.3, depending on the variable used as measure of marginal cost:

$$
\begin{aligned}
& \pi_{t}=\mu_{t}+\gamma_{t}+\phi h_{t}+\delta_{f} E_{t}\left(\pi_{t+1}\right)+\sum_{k=1}^{l} d_{k} \theta_{k, t}+\varepsilon_{t} \\
& \varepsilon_{t} \sim N\left(0, \sigma_{\varepsilon}{ }^{2}\right) \\
& \mu_{t}=\mu_{t-1}+\eta_{t} \text {, } \\
& \eta_{t} \sim N\left(0, \sigma_{\eta}^{2}\right) \\
& \gamma_{t}=\sum_{j=1}^{[s / 2]} \gamma_{j, t} \\
& t=1, \ldots, T
\end{aligned}
$$


where each $\gamma_{j, t}$ is generated by:

$$
\begin{aligned}
& {\left[\begin{array}{l}
\gamma_{j, t} \\
\gamma_{j, t}^{*}
\end{array}\right]=\left[\begin{array}{cc}
\cos \lambda_{j} & \sin \lambda_{j} \\
-\sin \lambda_{j} & \cos \lambda_{j}
\end{array}\right]\left[\begin{array}{l}
\gamma_{j, t-1} \\
\gamma_{j, t-1}^{*}
\end{array}\right]+\left[\begin{array}{c}
\omega_{j, t} \\
\omega_{j, t}^{*}
\end{array}\right]} \\
& j=1, \ldots,[s / 2]
\end{aligned}
$$

In the above expression for trigonometric seasonality, $\lambda_{j}=2 \pi j / \mathrm{s}$ is the seasonal frequency in radians, and $\omega_{j, t}, \omega_{j, t}^{*}$ are normally independent distributed seasonal disturbances with zero mean and common variance $\sigma_{\omega}^{2}$. To choose the intervention dummy variables $\theta_{k, t}$ we analysed the auxiliary residuals, which are smooth estimates of the disturbances of irregular, level and slope components. ${ }^{13}$

Equation (12) is also called measurement or observation equation containing variables that explain the observed inflation. Equations (13) through (15) form the state equations that characterize the dynamics of unobserved variables. Note that inflation trend follows a local level approach, compatible with nonstationarity, which is common in the literature. As to seasonality, component $\gamma_{t}$ can be seen as the sum of time-varying trigonometric cycles.

For the implementation of the Kalman filter algorithm, it is necessary that the model's equations are expressed in state-space form, i.e.:

$$
\begin{array}{r}
\pi_{t}=\left(\begin{array}{llll}
1 & 1 & 0
\end{array}\right) \boldsymbol{\alpha}_{\boldsymbol{t}}+\phi h_{t}+\delta_{f} E_{t}\left(\pi_{t+1}\right)+\boldsymbol{d}_{\boldsymbol{k}} \boldsymbol{\theta}_{\boldsymbol{k}, \boldsymbol{t}}^{\prime}+\left(\begin{array}{cccc}
\sigma_{\varepsilon} & 0 & 0 & 0
\end{array}\right) \boldsymbol{u}_{\boldsymbol{t}} \\
\boldsymbol{\alpha}_{\boldsymbol{t}}=\left(\begin{array}{ccc}
1 & 0 & 0 \\
0 & \cos \lambda_{j} & \sin \lambda_{j} \\
0 & -\sin \lambda_{j} & \cos \lambda_{j}
\end{array}\right) \boldsymbol{\alpha}_{\boldsymbol{t}-\mathbf{1}}+\left(\begin{array}{cccc}
0 & \sigma_{\eta} & 0 & 0 \\
0 & 0 & \sigma_{\omega} & 0 \\
0 & 0 & 0 & \sigma_{\omega}
\end{array}\right) \boldsymbol{u}_{\boldsymbol{t}}
\end{array}
$$

where $\boldsymbol{\alpha}_{\boldsymbol{t}}=\left(\begin{array}{lll}\mu_{t} & \gamma_{j, t} & \gamma_{j, t}^{*}\end{array}\right)^{\prime}$ and $\boldsymbol{u}_{\boldsymbol{t}}=\left(\begin{array}{llll}\varepsilon_{t} & \eta_{t} & \omega_{t} & \omega_{t}^{*}\end{array}\right)^{\prime}$

In other words, our model basically resembles a reduced-form new Keynesian Phillips curve, with inflation expectations term and output gap as explanatory variables. Nevertheless, it also captures, to some extent, past inflation behaviour through the decomposed trend

13 The inclusion of the cyclical component $\psi_{t}$ was also tested, but it was found to incorrectly capture some typical outlier episodes found in the cycles. Thus, the component was not considered at this estimation stage. 
and seasonality terms, in an attempt to mitigate an empirical deficiency that is commonly referred to in the literature. ${ }^{14}$

\subsection{Data and Econometric Approach}

Table 1 shows the series used to estimate Equations (11) through (15) as well as the multivariate analysis in section 4. Monthly GDP series at current prices, from April 2000 to May 2011 (source: http://www4.bcb.gov.br/?SERIESTEMP)was decomposed, following Equations (7) through (10), using the Kalman filter algorithm from the OxMetrics 5 package (STAMP module). The trend component obtained from the estimation is a good approximation for the potential output in the period. The difference between the observed series and its seasonally adjusted trend is the output gap. In this case, disregarding the error term, as its variance was very close to zero, we can easily assume that the cyclical component corresponds to the output gap. Similar reasoning was used to extract the output gap from the IBC-Br series.

Table 1: Monthly data series

\begin{tabular}{lll}
\hline \multicolumn{1}{c}{ Variable } & \multicolumn{1}{c}{ Proxy } & \multicolumn{1}{c}{ Source } \\
\hline Inflation & IPCA & IBGE \\
& PIB-M & IBGE \\
Output & IBC-Br & BCB \\
Inflation expectations & Median of daily expectations & FOCUS-BCB \\
Marginal cost & PIB-M and IBC-Br output gaps & UC-model \\
& Industrial capacity utilization rates (ICU) & CNI \\
\hline
\end{tabular}

Notes: The IBC-Br series is only available after January 2003. IPCA: Broad consumer price index; IBGE: Brazilian Institute of Geography and Statistics; BCB: Brazilian Central Bank; PIB-M: Monthly output series built by interpolation of the quarterly series published by the $\mathrm{BCB}$; IBC-Br: BCB's Index of Economic Activity; CNI: Brazil's National Confederation of Industry.

Figure 1 highlights the comparison of the series obtained from the PIB-M output gap, from the IBC-Br output gap and from relative deviations of the ICU, all of which are expressed as percentage.

${ }^{14}$ Fuhrer and Moore (1995) were the first to argue that standard new Keynesian price adjustment models could fail to explain persistence in the empirical process of inflation. 
The percentage difference between actual ICU and its average for the period (calculated as $80.87 \%$ ) was used to construct the deviations. Some clear patterns among all variables match the stylized facts in the Brazilian economy: first, a continuous economic activity growth period started in early 2006 and lasted until the first half of 2008; thereafter the subprime crisis caused a dramatic drop in activity. Second, a new period of economy growth apparently brought the observed output again above potential output and then more or less stabilized it over 2010. Inflation expectations were obtained from the Central Bank's FOCUS survey. Here, we used the median of daily expectations within each month with respect to the next month.

First, we tested a model similar to the one used in Harvey (2011), which consists of equation (11) and is identified in Table 2 as model I. Then, to highlight the importance of introducing inflation expectations in the Phillips curve model with unobserved components, we use Equation (12) (Model II). In both alternatives, the measure of marginal cost used is the output gap calculated from the monthly GDP provided by the BCB (PIB-M).

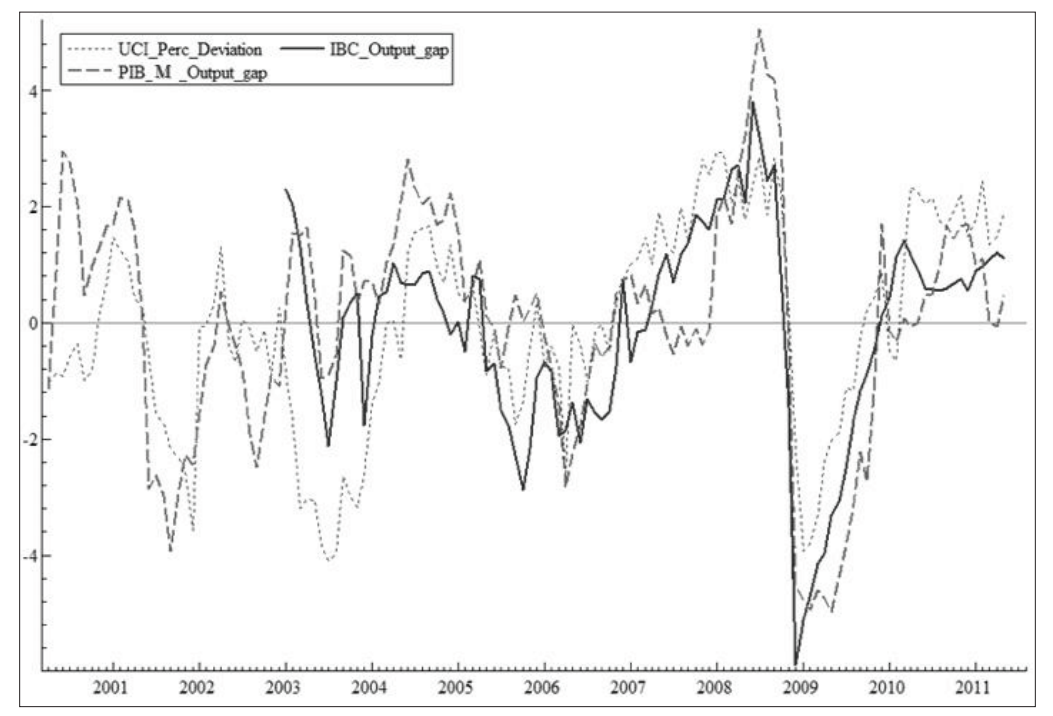

Figure 1: Comparison of economic activity series 
The third model concerns a Phillips curve that is identical to (12), but with ICU data instead of output gap. Finally, model IV again consists of the same Equation (12), with the difference that the output gap series was calculated using IBC-Br series. The inclusion of interventions in important due to unusual inflation movements, especially around 2002 and 2003.

Model evaluation followed usual fitting and residuals diagnostic statistics. With respect to fitting, the chief indicators contemplated in the estimation of the output gap and of the Phillips curve were the following: algorithm convergence, prediction error variance (PEV), and log-likelihood. According to Koopman et al. (2007), a good convergence is key to show that the model was properly formulated and has no fitting problems. Prediction error variance is the basic measure of goodness-of-fit which, in steady state, corresponds to the variance of the one-step-ahead forecast errors. Other diagnostic statistics analysed include Box-Ljung's Q statistics, for the assessment of residuals autocorrelation, and normality $(\mathrm{N})$ and heteroskedasticity $(\mathrm{H})$ results.

\subsection{Results}

In the output gap estimation, a "very strong" convergence and a relatively small prediction error variance were obtained. The recent global financial crisis and the resulting sharp decrease in all economic activity measures in the last quarter of 2008 and subsequent recovery are noteworthy.

Table 2 summarizes key results from the different models described in Section 3.2. In all cases, convergence was again "very strong," satisfying the main modeling criterion proposed by Koopman et al. (2007). 
Table 2: Phillips curve estimation results

\begin{tabular}{|c|c|c|c|c|c|c|c|c|}
\hline & PEV & Loglik & $R_{s}^{2}$ & $Q$ & $N$ & $H$ & $\delta_{f}$ & $\phi$ \\
\hline Model I (Harvey) & 0.052 & 143.43 & 0.54 & 29.31 & 0.04 & 0.56 & - & 0.017 \\
\hline$\pi_{t}=\mu_{t}+\gamma_{t}+\phi h_{t}+\sum_{k=1}^{l} d_{k} \theta_{k, t}+\varepsilon_{t}$ & & & & & & & & {$[0.41] \#$} \\
\hline Model II & 0.047 & 148.96 & 0.59 & 27.52 & 0.77 & 0.63 & 0.999 & 0.015 \\
\hline$\pi_{t}=\mu_{t}+\gamma_{t}+\phi h_{t}+\delta_{f} E_{t}\left(\pi_{t+1}\right)+\sum_{k=1}^{l} d_{k} \theta_{k, t}+\varepsilon_{t}$ & & & & & & & {$\left[3 \times 10^{-5}\right]$} & ] [0.38] \\
\hline Model III & 0.047 & 148.87 & 0.59 & 30.32 & 0.90 & 0.63 & 0.995 & 0.009 \\
\hline$\pi_{t}=\mu_{t}+\gamma_{t}+\phi I C U_{t}+\delta_{f} E_{t}\left(\pi_{t+1}\right)+\sum_{k=1}^{l} d_{k} \theta_{k, t}+\varepsilon_{t}$ & & & & & & & {$\left[3 \times 10^{-5}\right]$} & {$[0.66]$} \\
\hline Model IV & 0.029 & 117.97 & 0.45 & 26.16 & 3.46 & 0.58 & 1.08 & 0.034 \\
\hline$\pi_{t}=\mu_{t}+\gamma_{t}+\phi I B C h_{t}+\delta_{f} E_{t}\left(\pi_{t+1}\right)+\sum_{k=1} d_{k} \theta_{k, t}+\varepsilon_{t}$ & & & & & & & {$[0]$} & {$[0.001]$} \\
\hline
\end{tabular}

Source: Data obtained by the authors

Notes: \#Values in square brackets: p-value.

The interventions, in order of importance, and respective p-values for models I through III were as follows:

- Outlier in 2002/11. Model I: 1.35 [0]; model II: 1.26 [0]; model III: 1.27 [0]

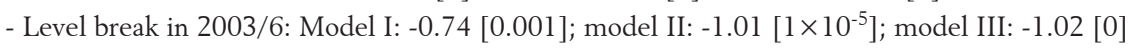

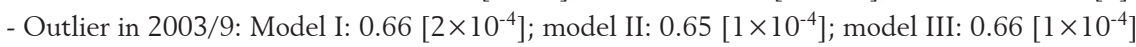

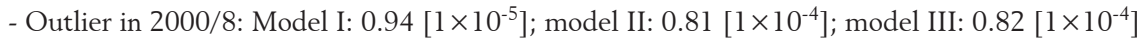

- Outlier in 2000/7: Model I: 0.83 [ $1 \times 10^{-4}$ ]; model II: 0.63 [0.003]; model III: 0.64 [0.002]

In model IV, the resulting interventions were:

- Level break in 2003/3: -0.75 [0]

- Outlier in 2003/6: -1.25 [0]

- Outlier in 2006/6: -0.36 [0.06].

As expected, the prediction error variance decreased from I to IV, indicating superior fit of the models that include inflation expectations (II through IV). Log-likelihood indicators underscore this conclusion, as they increased from I to III. In the case of model IV, the reduction is more a result of sample size than of the goodness of fit, given that log-likelihood is an absolute and cumulative indicator.

The traditional coefficient of determination undergoes a slight change in case of seasonal data, $R_{s}^{2}$, and measures the relative performance of the specified model in relation to a simple random walk with drift and fixed seasonality. 
Again, the result is better for models II and III. According to BoxLjung's Q statistics, serial correlation of residuals is absent in all models and significance is lower than $0.1 \%$.

With values lower than one, heteroskedasticity $(\mathrm{H})$ tests indicate that the variance of residuals slightly decreases over time. Unequivocally, this results from the improvement of the inflation targeting regime in Brazil, with an increasingly larger convergence of the inflation rate towards the targets.

Even in model IV, with a more recent sample, the pattern signals at gradually lower variances. As to normality $(\mathrm{N})$, the models clearly succeeded on the test, based on Doornik-Hansen's statistic whose critical value at a $5 \%$ significance level is 5.99 .

The slopes $(\phi)$ of the different Phillips curve specifications - which are the coefficients for output gap and ICU deviation at the end of the sample - were positive in all cases, as theoretically expected, though not statistically significant in cases I to III. On the other hand, the output gap measure calculated based on the IBC-Br series was positively correlated with the inflation rate, with a high level of significance, although the amount of available data is smaller. The comment made by Tombini and Alves (2006), that smaller coefficients than most of those described in the literature are due to the monthly frequency of data, applies here.

In regard to the coefficients of inflation expectations, the values showed high statistical significance and are close to one. Note that, although we do not impose long-run verticality of the Phillips curve, since the lagged inflation term is not made explicit, the results on $\delta_{\mathrm{f}}$ suggest that such feature is present in the Brazilian economy, as already showed by Tombini and Alves (2006) and other studies.

Test statistics particularly indicate a fitting improvement as we move from an approach without inflation expectations, as in Harvey (2011), to an approach that includes them. However, among models using output gap measures and the ICU deviations, there is no clear superiority, when it comes to fitting.

Figure 2 shows the decomposition obtained in model II, which performed clearly better than the model adapted from Harvey (2011). 
The first chart compares monthly observed inflation values (black line) with the decomposition into trend, regression and intervention effects (gray line). The middle chart shows seasonal effects. The figures correspond to the percentage contribution in price fluctuation due to seasonality. Note also that the variance of this effect decreases in more recent years, with a sharp increase in the effect in February and decrease in the effect in June over the last two years.

Finally, the lower graph shows the irregular component. Considering that the period between late 2002 and mid-2003 had the three most discrepant observations regarded as outliers, this chart also depicts some gradual reduction in the variability of disturbances.

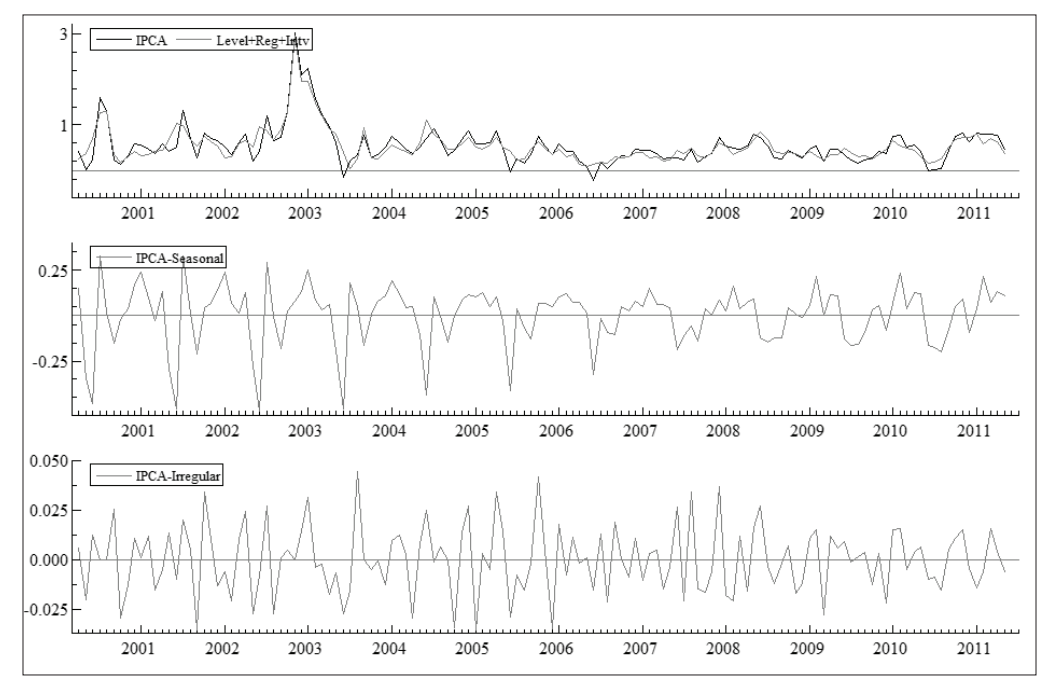

Figure 2: Inflation decomposition - Model II

\section{Multivariate Estimation}

Complementing the previous analysis, we fitted a bivariate model, in which inflation and output are jointly decomposed into unobserved components. This specification has the advantage of averting the exogenous estimation of the output gap, as it is implicitly present in the output equation. In this case, we have a vector of observations that now relies on two seemingly unrelated time series equations (SUTSE). 
The joint specification of inflation and output differs from Harvey (2011) because of the introduction of the seasonal component and, especially, of the expectations term. Our main model is now:

$\left[\begin{array}{l}\pi_{t} \\ y_{t}\end{array}\right]=\left[\begin{array}{l}\mu_{t}^{\pi} \\ \mu_{t}^{y}\end{array}\right]+\left[\begin{array}{l}\gamma_{t}^{\pi} \\ \gamma_{t}^{y}\end{array}\right]+\left[\begin{array}{l}\psi_{t}^{\pi} \\ \psi_{t}^{y}\end{array}\right]+\delta_{f}\left[\begin{array}{c}E_{t}\left(\pi_{t+1)}\right) \\ 0\end{array}\right]+\left[\begin{array}{l}\sum_{k=1}^{l} d_{k} \theta_{k, t}^{\pi} \\ \sum_{k=1}^{m} f_{k} \theta_{k, t}^{y}\end{array}\right]+\left[\begin{array}{c}\varepsilon_{t}^{\pi} \\ \varepsilon_{t}^{y}\end{array}\right]$

where $\theta_{k, t}^{\pi}$ and $\theta_{k, t}^{y}$ represent the sets of outliers considered for the inflation and output series respectively.

The link between the series in the SUTSE approach is generally established by the correlations of errors of one or more components. Following Harvey (2011), we assume the cycles have the same autocorrelation function and spectrum. In other words, inflation and output cycles are modeled as "similar cycles". In algebraic terms, supposing $\boldsymbol{\psi}_{\boldsymbol{t}}=\left(\psi_{t}^{\pi}, \psi_{t}^{y}\right)^{\prime}$,

$$
\begin{aligned}
& {\left[\begin{array}{l}
\boldsymbol{\psi}_{t} \\
\boldsymbol{\psi}_{t}^{*}
\end{array}\right]=\left[\rho\left(\begin{array}{cc}
\cos \lambda_{c} & \sin \lambda_{c} \\
-\sin \lambda_{c} & \cos \lambda_{c}
\end{array}\right) \otimes \boldsymbol{I}_{2}\right]+\left[\begin{array}{l}
\boldsymbol{\psi}_{t-1} \\
\boldsymbol{\psi}_{t-1}^{*}
\end{array}\right]+\left[\begin{array}{l}
\boldsymbol{\kappa}_{t} \\
\boldsymbol{\kappa}_{t}^{*}
\end{array}\right]} \\
& t=1, \ldots, T
\end{aligned}
$$

where $\boldsymbol{\kappa}_{\boldsymbol{t}}$ and $\boldsymbol{\kappa}_{\boldsymbol{t}}^{*}$ are $2 \times 1$ error vectors, such that $E\left(\boldsymbol{\kappa}_{\boldsymbol{t}} \boldsymbol{\kappa}_{\boldsymbol{t}}\right)=\boldsymbol{E}\left(\boldsymbol{\kappa}_{t}^{*} \boldsymbol{\kappa}_{\boldsymbol{t}}^{* \prime}\right)=\boldsymbol{\Sigma}_{\boldsymbol{\kappa}}$, and $\boldsymbol{\Sigma}_{\boldsymbol{\kappa}}$ is a 2 x 2 covariance matrix and $E\left(\boldsymbol{\kappa}_{\boldsymbol{t}} \boldsymbol{\kappa}_{\boldsymbol{t}}^{* \prime}\right)=\mathbf{0}$. Figure 3 shows a joint plot of the cyclical components that were separately obtained from inflation and output, which gives a sense of inflation and output gaps. As in Harvey (2011), although they naturally have some correlation, thus justifying the similar cycles assumption, the two series have a time-varying relationship, which calls for the UC model.

The series can also be expressed in state-space form, with each component now being a vector. The inflation trend component again follows a local level model, as in (13), and the output component conforms to a smooth trend model, as in (8) and (9). Seasonality here is also allowed to be stochastic, in order to check its variability in the inflation series. 


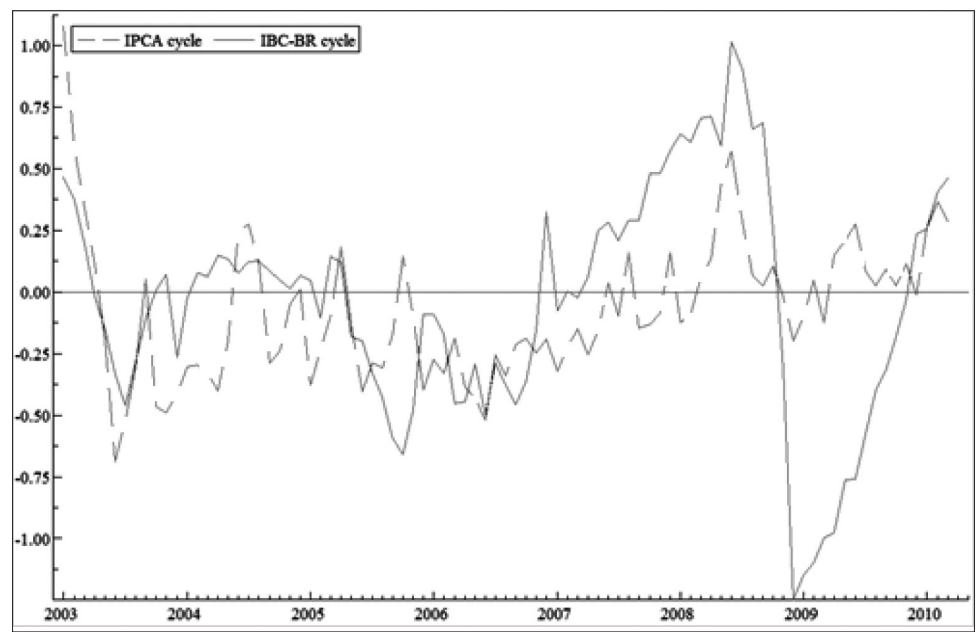

Figure 3 - Cycles obtained from univariate models for inflation and output (IBC-Br)

The cyclical component of inflation can be broken down into two independent parts, as follows:

$$
\psi_{t}^{\pi}=\beta \psi_{t}^{y}+\psi_{t}^{\pi^{*}}
$$

where $\beta=\frac{\operatorname{Cov}\left(\psi_{t}{ }^{\pi}, \psi_{t}{ }^{y}\right)}{\operatorname{Var}\left(\psi_{t}{ }^{y}\right)}=\frac{\operatorname{Cov}\left(\kappa_{t}{ }^{\pi}, \kappa_{t}{ }^{y}\right)}{\operatorname{Var}\left(\kappa_{t}{ }^{y}\right)}$ and $\psi_{t}{ }^{\pi^{*}}$ is a cyclical component specific to inflation.

Thus, the inflation equation may be rewritten as:

$$
\begin{aligned}
& \pi_{t}=\mu_{t}{ }^{\pi}+\gamma_{t}+\beta \psi_{t}{ }^{y}+\psi_{t}^{\pi^{*}}+\varepsilon_{t}{ }^{\pi} \\
& \varepsilon_{t}{ }^{\pi} \sim N\left(0, \sigma_{\varepsilon}{ }^{2}\right)
\end{aligned}
$$

Considering that the cycle of the output equation gives a good notion about the output gap, as occurred in Section 3, and that disturbances $\kappa_{t}^{\pi}$ and $\kappa_{t}{ }^{y}$ are perfectly correlated, coefficient $\beta$ corresponds to parameter $\phi$ of the univariate Phillips curve, or its slope. Therefore, from the correlation matrix of cycles, one obtains $\phi=\beta$. Additionally if we regard $\mu_{t}{ }^{\pi}$ as being expected inflation, Equation (19) reduces to Model IV equation shown in Table 3 
In the bivariate case, three basic specifications are tested. Again, a similar approach to that of Harvey (2011) is compared with the model built above, in which one includes the future inflation expectations term, as shown in Equation (16). They are represented as models V and VI. Finally, (16) through (19) are also employed considering the IBC-Br as proxy for $\mathrm{y}_{t}$ (Model VII).

The relevant goodness-of-fit criterion in this case is a correlation matrix for the prediction error variance and the log-likelihood. We only show test diagnostics referring to the inflation equation in (16), since our main interest here is on Phillips curve estimations.

\subsection{Results}

Multivariate estimates again reveal that including expectations improves the model's fit and determination, as one can easily check from log-likelihood and $R_{s}^{2}$ outcomes. It is also important to highlight that model V had a "weak" algorithm convergence compared to a "very strong" convergence in model VI. The comparison with model VII is hindered simply because the samples are different, but a similar pattern can be detected in the coefficients for inflation expectations and output gap. When the IBC-Br is used, its parameter shows a greater sensitivity of inflation than when PIB-M is employed as a measure of the output gap. This result is probably due to the nature of both series. Intuitively, a properly measured index of economic activity, such as the IBC-Br is expected to have greater impact on inflation than a monthly series built by mere interpolation of quarterly series. 
Table 3 - Estimation results - bivariate case

\begin{tabular}{lllllllllll}
\hline & Loglik & $R_{s}^{2}$ & $Q$ & $N$ & $H^{\dagger}$ & $\delta_{f}$ & $\phi$ \\
\hline
\end{tabular}

Model V (Harvey):

$\left[\begin{array}{l}\pi_{t} \\ y_{t}\end{array}\right]=\left[\begin{array}{l}\mu_{t}^{\pi} \\ \mu_{t}^{y}\end{array}\right]+\left[\begin{array}{l}\gamma_{t}^{\pi} \\ \gamma_{t}^{y}\end{array}\right]+\left[\begin{array}{l}\psi_{t}^{\pi} \\ \psi_{t}^{y}\end{array}\right]+\left[\begin{array}{l}\sum_{k=1}^{l} d_{k} \theta_{k, t}^{\pi} \\ \sum_{k=1}^{m} f_{k} \theta_{k, t}^{y}\end{array}\right]+\left[\begin{array}{l}\varepsilon_{t}^{\pi} \\ \varepsilon_{t}^{y}\end{array}\right]$

$\begin{array}{lllllll}604.39 & 0.57 & 19.39 & 2.95 & 0.43 & - & 0.028^{*}\end{array}$

Model VI (PIB-M)

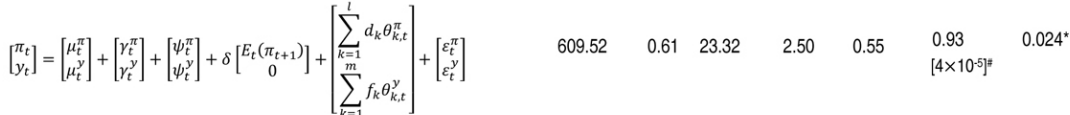

Model VII (IBC-Br)

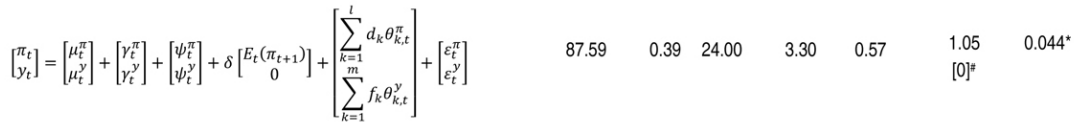

Source: Data obtained by the authors

Notes: ${ }^{*}$ The significance of parameter $\phi$ is not available as this parameter could only be indirectly estimated, as explained in (18) and (19).

\#: Values in square brackets: p-value.

†: Statistics $R_{S}^{2}, Q, N$ and $H$ refer only to the inflation equation.

The interventions considered in the inflation equation in models V and VI, in order of importance, and the respective $\mathrm{p}$-values were:

- Outlier in 2002/11. Model V: 1.41 [0] ; Model VI: 1.29 [0]

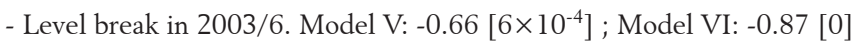

- Outlier in 2003/9. Model V: $0.71\left[3 \times 10^{-4}\right]$; Model VI: $0.67\left[3 \times 10^{-4}\right]$

- Outlier in 2000/8. Model V: 0.61 [0.005] ; Model VI: 0.56 [0.008]

In the output equation, level break in 2008/12. Model V: -0.09 [0]; Model VI: -0.09 [0].

In model VII, the resulting interventions were:

- Outlier in 2003/6: -1.16 [0]

- Level break in 2003/2: $-0.74\left[9 \times 10^{-4}\right]$

- Outlier in 2003/9: 0.55 [0.005].

Figure 4 shows the resulting components of model VII, where we used IBC-Br data. As opposed to Figure 2, recent dynamics of inflation in Brazil was rather less unstable. Particularly the seasonal effects proved to be relatively constant, although a reminder about the smaller size of the sample should be made. Taking a closer look at the period between 2006 and early 2008, there is clearly less variability in the components of inflation than in the rest of the sample. 
This illustrates the relatively calm pre-crisis setting in terms of monetary policy tensions, which was also in place in Brazil.

As to GDP, seasonal effects were reasonably constant in the sample. On the other hand, the cyclical component, which gives some notion about the output gap, showed a more erratic behaviour, with a sharpened drop at the end of $2008,{ }^{15}$ due to the impact of the U.S. subprime crisis. Also, note how the modeling of similar cycles allowed for a contemporaneous pattern in both series coinciding with the crisis episode.

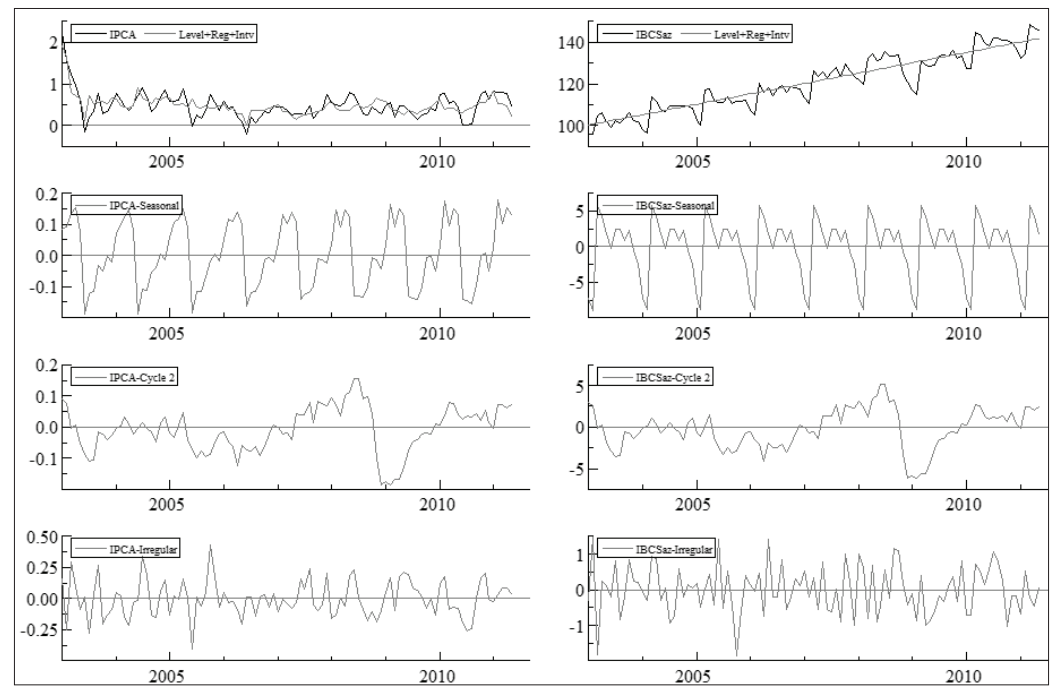

Figure 4 - Inflation and output (IBC-Br) - Bivariate model VII

Note: The IBC-Br is constructed based on the value of 100 in 2002. Inflation is expressed in monthly rates.

\section{Extensions}

Two analyses were added to the basic models. The first one concerns the flattening of the Phillips curve, observed in studies for some developed countries. As shown by Kuttner and Robinson (2010),

15 The behaviour of IBC-Br in late 2008 would also suggest a level break in trend, which was not feasible in practice due to restrictions on the algorithm and to the relatively small amount of observations. 
the parameter $\phi$ of Equation (12), which represents the response of the observed inflation to the output gap, has decreased in empirical analyses for the United States and Australia. A possible explanation is that, as inflation expectations become better anchored, the inflation response to supply shocks tends to be accommodated. An alternative justification states that the frequency of price-setting may depend on the average inflation rate, hence monetary policy could indirectly influence the slope of the Phillips curve, by lowering the inflation trend. As a first attempt to investigate whether the same occurs in Brazil, a variant of models I to IV was tested, in which the output gap coefficient was allowed to vary over time, i.e., we now have $\phi_{t}, t=(\mathrm{Jan} / 2003, \ldots, \mathrm{May} / 2011)$.

In this case, a smoothing spline was used, in which the slope of the Phillips curve varies according to:

$$
\begin{aligned}
& \left(\phi_{t}-\phi_{t-1}\right)=\left(\phi_{t-1}-\phi_{t-2}\right)+u_{t} \\
& u_{t} \sim N\left(0, \sigma_{u}{ }^{2}\right)
\end{aligned}
$$

The estimation of this new model is carried out with Equations (12) through (15) plus (20), which is an additional state equation.

The prediction error variances of this estimation were slightly lower than that of the models in which $\phi$ was fixed, pointing to an intuitively better fit. Results indicate that the flattening of the Phillips curve has recently been in progress in Brazil as well, as shown in Figure 5. Although model IV generated a general decline in the Phillips curve slope just until 2009, the general trend is still downwards. This result confirms the importance of time-varying parameters in Phillips curve estimations, as underscored by Sachsida, Ribeiro and Santos (2009). Implications of the flattening Phillips curve in the literature are twofold: On the one hand, the potential cost of disinflation in terms of lost output tend to increase, but on the other hand, increases in economic activity may cause gradually smaller inflationary pressures. Tombini and Alves (2006) highlight that the mere uncertainty caused by the 2002 electoral crisis would have been strong enough to change the parameters of the reduced form Phillips curve, leading to higher costs of disinflation. The authors also find evidence of reduction in parameter $\phi_{t}$. 


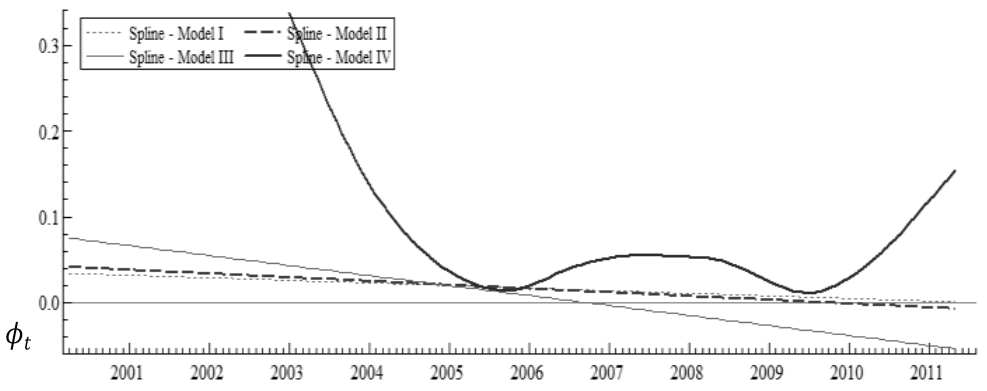

Figure 5 - Dynamics of output gap coefficients in the Phillips Curve

The model finally assesses the forecasting power of a Phillips curve model by comparing observed inflation with the one calculated throughout the models, based on the minimization of one-stepahead forecast errors. Stock and Watson (2008) reviewed Phillips curve based models in their ability to forecast inflation and observed good performance in some cases. Nevertheless, Atkeson and Ohanian (2001) advocate that these forecasts tend to be worse than those based on simple univariate models. The widespread use of the NKPC in the literature and in actual policy therefore requires its forecasting power to be evaluated. ${ }^{16}$

In the present study, the last 12 observations were excluded and the one-step-ahead inflation forecast was estimated for the period between April 2010 and March 2011. Mean squared error figures for each model are shown in Table 4.

Note that the models including inflation expectations had a higher forecasting power than Harvey's variant, again corroborating the main argument of the present study. This occurred both in the univariate and bivariate cases. In the univariate specification, output gap extracted from IBC-Br was not very successful, but in the bivariate case, it yielded the lowest mean squared error among all estimations, despite its smaller number of observations.

${ }^{16}$ Araujo and Guillen (2008) test the forecasting power of different Phillips curves based on output gap specifications and conclude that the best performance was obtained by the output gap extracted in a multivariate method of unobserved components. 
Table 4 - Mean squared forecast error - different specifications

\begin{tabular}{lcccccccc}
\hline Model & I & II & III & IV & V & VI & VII & Naive \\
\hline $\begin{array}{l}\text { Mean } \\
\text { squared } \\
\text { error: }\end{array}$ & 0.0258 & 0.0235 & 0.0215 & 0.0269 & 0.0222 & 0.0208 & 0.0184 & 0.0296 \\
\hline
\end{tabular}

Source: Data collected by the authors

Forecasting power clearly increases in all cases when a multivariate specification is used. Finally, the mean squared error of a naive inflation model was calculated. In such a model, expected inflation value is forecasted by its current value, i.e., $E_{t-1} \pi_{t}=\hat{\pi}_{t}=\pi_{t-1}$. Our Phillips curve outperformed this specification, which corresponds to the last column.

\section{Conclusions}

Given the clear-cut empirical difficulties surrounding the Phillips Curve, the present study assessed inflation dynamics using an unobserved components approach for the Brazilian economy. By modifying Harvey's (2011) approach, introducing an inflation expectation term in the Phillips curve, the model manages to parsimoniously express the dynamic relation between inflation and output gap. With the additional advantage of the graphical result, which allows a more direct economic interpretation of the components, we highlight the variability of the seasonal component of inflation, even within a sample of relatively few years. The relative reduction in this variability in the past years suggests that the inflation targeting system has contributed to reducing not only the inflation rates, but also their volatility within each year, at least until the subprime crisis effects came into place.

Output gap obtained in the trend-cycle models from the PIB-M series and the ICU deviation series did not yield good statistical results for the analysed Phillips curve, even though positive coefficients were found. In the case of an output gap extracted from the IBC-Br series, the result was clearly better, showing that this index, still not widespread in the literature, may be gradually more 
important for Brazilian monetary policy. Bivariate estimation clearly produced more attractive results and strengthened our results from the univariate estimation.

The analysis of the Phillips curve slope, represented by parameter $\phi_{t}$ indicates a flattening Phillips curve in Brazil, as in Tombini and Alves (2006) and similarly to what is observed in developed countries, as reported by Kuttner and Robinson (2010). Finally, our model's forecasting power was shown to outperform both a simple forecasting model and Harvey's formulation, in terms of squared forecast errors.

Some issues could be subject of investigation of future research. For example, a comparison between the performance of output gap with that of other measures, such as unit labour cost or deviation from the natural rate of unemployment. One could also look at another approach that considers different dynamics of free and administered prices, and even possible distinctions between tradable and nontradable goods. Finally, comparisons to related countries using a similar approach could also prove useful.

\section{References}

ADAM, K.; PADULA, M. Inflation dynamics and subjective expectations in the United States. Economic Inquiry, v. 49, n. 1, p. 13-25, Jan. 2011.

ARAUJO, C. H.; GAGLIANONE, W. P. Survey-based inflation expectations in Brazil. In: BIS Papers. Monetary policy and the measurement of inflation: prices, wages and expectations, Bank for International Settlements, n. 49, p. 107-113, 2010.

ARAUJO, C. H.; GUILLEN, O. Previsão de inflação com incerteza do hiato do produto no Brasil. Anais do XXXVI Encontro Nacional de Economia, Salvador, 2008.

ARRUDA, E.; FERREIRA, R.; CASTELAR, I. Modelos lineares e não lineares da curva de Phillips para previsão da taxa de inflação no Brasil. Anais do XXXVI Encontro Nacional de Economia, Salvador, 2008.

ATKESON, A.; OHANIAN, L. E. Are Phillips curves useful for forecasting inflation? Federal Reserve Bank of Minneapolis Quarterly Review, v. 25, n. 1, Winter 2001.

BASISTHA, A.; NELSON, C. R. New measures of the output gap based on the forward-looking New Keynesian Phillips curve. Journal of Monetary Economics, v. 54, n. 2, p. 498-511, Mar. 2007.

BONOMO, M. A.; BRITO, R. D. Regras monetárias e dinâmica macroeconômica no Brasil: Uma abordagem de expectativas racionais. Revista Brasileira de Economia, v. 56, n. 4, p. 551-589, Oct./Dec. 2002. 
CALVO, G. Staggered pricing in a utility-maximizing framework. Journal of Monetary Economics, v. 12, n. 3, p. 383-398, Sept. 1983.

CHRISTIANO, L. J.; EICHENBAUM, M.; EVANS, C. L. Nominal rigidities and the dynamic effects of a shock to monetary policy. Journal of Political Economy, v. 113, n. 1, p. 1-45, 2005.

CORREA, A.; MINELLA, A. Mecanismos não lineares de repasse cambial: um modelo de curva de Phillips com threshold para o Brasil. Anais do XXXIII Encontro Nacional de Economia, Natal, 2005.

FASOLO, A. M.; PORTUGAL, M. S. Imperfect rationality and inflationary inertia: a new estimation of the Phillips curve for Brazil. Estudos Econômicos, São Paulo, v. 34, n. 4, p. 725-776, Oct./Dec. 2004.

FUHRER, J.; MOORE, G. Inflation persistence. Quarterly Journal of Economics, v. 110, n. 1, p. $127-$ $159,1995$.

GALI, J.; GERTLER, M. Inflation dynamics: A structural econometric analysis. Journal of Monetary Economics, v. 44, n. 2, p. 195-222, Oct. 1999.

GOODFRIEND, M.; KING, R. G. The great inflation drift. NBER Working Paper Series, n. 14862, Apr. 2009.

GORDON, R. J. The time-varying NAIRU and its implications for economic policy. Journal of Economic Perspectives, v. 11, n. 1, p. 11-32, 1997.

HARVEY, A. Forecasting, Structural Time Series Models and the Kalman Filter. Cambridge, UK: Cambridge University Press, 1989.

Modelling the Phillips curve with unobserved components. Applied Financial Economics, v. 21, n. 1-2, p. 7-17, 2011.

HENZEL, S.; WOLLMERSHÄUSER, T. The New Keynesian Phillips curve and the role of expectations: Evidence from the CESifo World Economic Survey. Economic Modelling, v. 25, p. 811-832, 2008.

KOOPMAN, S. et al. STAMP 8: Structural Time Series Analyser, Modeller and Predictor. London: Timberlake Consultants, 2007.

KUTTNER, K; ROBINSON, T. Understanding the flattening Phillips curve. The North American Journal of Economics and Finance, v. 21, n. 2, p. 110-125, Aug. 2010.

LEE, J.; NELSON, C. R. Expectation horizon and the Phillips curve: The solution to an empirical puzzle. Journal of Applied Econometrics, v. 22, n. 1, p. 161-178, Jan./Feb. 2007.

MAVROEIDIS, S. Identification issues in forward looking models estimated by GMM, with an application to the Phillips curve. Journal of Money Credit and Banking, v. 37, n. 3, p. 421-448, June 2005.

MISE, E.; KIM, T-H.; NEWBOLD, P. On suboptimality of the Hodrick-Prescott filter at time series endpoints. Journal of Macroeconomics, v. 27, n. 1, p. 53-67, Mar. 2005.

NASON, J. M.; SMITH, G. W. Identifying the new Keynesian Phillips curve. Journal of Applied Econometrics, v. 23, n. 5, p. 525-551, Aug. 2008a.

The new Keynesian Phillips curve: Lessons from single-equation econometric estimation. Federal Reserve Bank of Richmond Economic Quarterly, v. 94, n. 4, p. 361-395, Fall 2008b.

PHILLIPS, A. W. The relation between unemployment and the rate of change of money wage rates in the United Kingdom, 1861-1957. Economica, v. 25, n. 100, p. 283-99, Nov. 1958.

ROBERTS, J. M. New Keynesian economics and the Phillips curve. Journal of Money, Credit and Banking, v. 27, n. 4, p. 975-984, Nov. 1995.

RUDD, J.; WHELAN, K. Modeling inflation dynamics: A critical review of recent research. Journal of Money, Credit and Banking, v. 39, n. 1, p. 155-170, Feb. 2007.

SACHSIDA, A.; RIBEIRO, M.; SANTOS, C. H. A curva de Phillips e a experiência brasileira. Textos para Discussão IPEA, Brasília, n. 1429, out. 2009.

SAMUELSON, P. A.; SOLOW, R. M. Analytical aspects of anti-inflation policy. American Economic Review, v. 50, n. 2, p. 177-194, May 1960. 
SCHWARTZMAN, F. F. Estimativa de curva de Phillips para o Brasil com preços desagregados. Economia Aplicada, Ribeirão Preto, v. 10, n. 1, p. 137-155, jan./mar. 2006.

STOCK, J. H.; WATSON, M. W. Phillips curve inflation forecasts. NBER Working Paper Series, $\mathrm{n}$. 14322, Sept. 2008.

TOMBINI, A. A.; ALVES, S. A. L. The recent Brazilian disinflation process and costs. BCB Working Paper Series, Banco Central do Brasil, n. 109, June 2006.

VOGEL, L. The relationship between the hybrid new Keynesian Phillips curve and the NAIRU over time. Macroeconomics and Finance Series, Hamburg University, n. 3, Oct. 2008.

WONGWACHARA, W.; MINPHIMAI, A. Unobserved components models of the Phillips relation in the ASEAN Economy. Journal of Economics and Management. v. 5, n. 2, p. 241-256, 2009.

WOODFORD, M. Interest and Prices: Foundations of a Theory of Monetary Policy. Princeton: Princeton University Press, 2003. 